\title{
BEYOND THE EITC: THE EFFECT OF REDUCING THE EARNED INCOME TAX CREDIT ON LABOR FORCE PARTICIPATION
}

\author{
Jeremy G. Moulton, Alexandra Graddy-Reed, and Lauren Lanahan
}

\begin{abstract}
We examine variation in the Earned Income Tax Credit (EITC) program when households lose eligibility due to children aging out of the program. This change in eligibility offers a framework for assessing whether the aim of the program of increasing work incentives extends beyond the time recipients qualify for the EITC. We estimate the impact of reducing the EITC on mothers'labor force participation using a combination of difference-in-differences and household fixed effects models, using data from the National Longitudinal Survey of Youth 1979. The results indicate that some of those who most likely qualify for the EITC (unmarried, less educated mothers) leave the workforce when they lose the benefit.
\end{abstract}

Keywords: labor supply, EITC, tax policy

JEL Codes: H24, H31, J22

\section{INTRODUCTION}

he Earned Income Tax Credit (EITC) is the largest U.S. federal cash-transfer program for low-income families. In 2013 alone, 28 million families received more than $\$ 66$ billion. ${ }^{1}$ As of 2014 , households could increase their gross incomes by up to 45 percent depending on their eligibility qualifications, ${ }^{2}$ with $\$ 2,407$ as the average amount of EITC received. ${ }^{3}$

\footnotetext{
1 EITC Central, "EITC Information for the Press," http://www.eitc.irs.gov/EITC-Central/press/.

2 Based on the structure of the program in 2014, single filers with three children with an earned income of $\$ 13,650$ are eligible for the largest cash-transfer of $\$ 6,143$.

3 EITC Central, “About EITC,” http://www.eitc.irs.gov/EITC-Central/abouteitc.
}

\footnotetext{
Jeremy G. Moulton: Department of Public Policy, University of North Carolina-Chapel Hill, Chapel Hill, NC, USA (moulton@email.unc.edu)

Alexandra Graddy-Reed: Price School of Public Policy, University of Southern California, Los Angeles, CA, USA (graddyre@price.usc.edu)

Lauren Lanahan: Department of Management, Lundquist College of Business, Eugene, OR, USA (Ilanahan@ uoregon.edu)
} 
In an effort to estimate the impact of the EITC program on labor force participation (LFP), many studies have set up natural experiments centered around EITC expansions (Cancian and Levinson, 2006; Dickert, Houser, and Scholz, 1995; Eissa and Hoynes, 2004, 2006; Eissa and Liebman, 1996; Hotz, Mullin, and Scholz, 2002; Meyer and Rosenbaum, 2001; Meyer, 2002; Scholz, 1994, 1996). ${ }^{4}$ To extend this discussion, we approach the issue from a different angle. Namely, we examine the effect of EITC reduction on LFP when households lose eligibility based on the qualifying child requirement. ${ }^{5}$ Rather than focusing on entry or expansion of the program, we exploit variation in the EITC based on exit. To estimate this effect, we exploit within household variation. Our results imply that some of those who most likely qualify for the EITC (unmarried, less educated mothers) leave the workforce when the EITC benefit stops.

The contributions of the paper are twofold. First, this paper offers a new approach to examine the effects of income and wage variation on LFP. More specifically, this design presents an opportunity to examine whether the impacts of the program extend beyond the credit itself. As explicitly stated by the Internal Revenue Service, Congress originally approved the tax credit legislation in 1975 to increase incentives to work. ${ }^{6}$ Considerable research has exploited variation in terms of EITC expansion to examine a series of short run impacts of the program; however, we have not seen any studies that examine whether the program has a lasting effect and adjusts one's taste for work. While the explicit intention of the program is designed to incentivize work, arguably the implicit intention of this anti-poverty social program is that participants remain engaged in the workforce beyond their tenure of eligibility. By estimating the effect of LFP when the size of the credit decreases and ultimately stops, we examine the after effects of the EITC program on workforce activity.

Second, we offer an alternative empirical approach for this literature. A large portion of the EITC literature has employed between-group comparisons, specifically differencein-differences (DD) research designs (Eissa and Hoynes, 2004; Eissa and Liebman, 1996; Evans and Garthwaite, 2014; Hotz and Scholz, 2006; Meyer and Rosenbaum, 2001). These analyses centrally rest on the composition of a sufficient control group and an exogenous policy shock. Although these previous studies have presented robust estimates, the methodological hurdles inherent in this research design are open to criticism, given the threat of selection bias for the control group. To strengthen the validity of this approach, we build upon this common design by including household fixed effects. Drawing from the literature, we identify the treatment and control groups based on educational attainment and marital status. With this approach we estimate the differential

\footnotetext{
4 EITC program expansions took place in 1986, 1990, 1993, 2001, and 2009.

5 We use the terms "eligible" and "qualifying" interchangeably in the text.

6 EITC Tax Preparer Toolkit, "Handling the Most Common Error," https://www.eitc.irs.gov/Tax-PreparerToolkit/toosandtips/mostcommonerrors.
} 
effect of the EITC on labor supply by comparing activities within households rather than solely comparing differences between groups (e.g., mothers versus non-mothers).

We use the U.S. Bureau of Labor Statistics' National Longitudinal Survey of Youth 1979 (NLSY79) to examine the after effect of the EITC program on the labor supply of households who lose the tax credit due to children who passed the EITC qualifying child eligibility age threshold. ${ }^{7}$ This empirical approach allows us to examine the impact of the program for an older and often overlooked cohort of mothers who have children entering adulthood. We recognize that this approach has its own shortcomings. Given the structure of the program, the loss of eligibility is not random but rather predictable and depends on household choices. We aim to overcome this challenge not only by including a control group but also by accounting for household fixed effects that capture time-invariant factors that confound labor supply choices.

We find evidence suggesting that EITC reduction and exit decrease LFP. Most notably, losing one qualifying child decreases LFP by 3.3 percentage points, relative to households eligible for the EITC program. When comparing those most likely to be eligible for the EITC - unmarried, less educated mothers - to a control group of college educated unmarried mothers, the effect is larger with an 8.0 percentage point decrease.

The paper is organized as follows. Section II overviews the policy context for the EITC program and places this particular approach — focusing on EITC exit rather than program expansion - within the larger literature. Section III outlines the research design, data, sample, and stratification, and addresses concerns pertaining to identification. Section IV presents our research methods. Section V presents the results and includes additional specifications. Section VI discusses the results, considers these findings within the context of previous research, and offers directions for future research.

\section{EITC POLICY CONTEXT AND PREVIOUS LITERATURE}

The EITC program is a refundable federal income tax credit designed for households with low to moderate incomes. This anti-poverty measure is designed to incentivize work and offers a refundable tax credit to households that meet income and structure requirements. Households with income approximately under 125 percent of the federal poverty level qualify. The primary target population and large majority of recipients for this credit are single filer, low-income earners with qualifying children. As specified by the program, qualifying children must meet a series of age, relationship, and residency tests. ${ }^{8}$ Dependent children qualify until they turn age 19. If the dependent child is enrolled full time in college, the child qualifies until age 24 . The program also provides modest support for a much smaller portion of very-low-income earners who do not have

\footnotetext{
Bureau of Labor Statistics, "The NLSY79," http://www.bls.gov/nls/nlsy79.htm.

8 Dependents with qualifying disabilities are not subject to an age requirement.
} 
a qualifying child. ${ }^{9}$ However, we follow the literature and focus on the former group unmarried mothers in particular - who face both income and household requirements.

The design of the credit follows a pyramid schedule, which includes a phase-in and phase-out region. ${ }^{10}$ The credit phases in at a fixed percentage from the first dollar of earned income until it reaches a maximum. The maximum credit is constant for an income range, and then the credit phases out at a smaller fixed percentage until the household income reaches a cap (Figure 1). The size of the credit depends on whether the household has a single filer or is a married couple filing jointly, as well as on the number of qualifying children. It is worth noting that after 2008 the program differentiated among households with one, two, and three or more children. The recent expansion that includes a third eligible child effectively increased the maximum size of the credit by roughly 12.5 percent. ${ }^{11}$

Given the design of the program, research directed toward LFP is prominent in the literature. In their literature review, Hotz and Scholz (2003) highlight three trends. First, the EITC program positively affects labor supply along the extensive margin for unmarried households - unmarried mothers in particular (Dickert, Houser, and Scholz, 1995; Eissa and Hoynes, 2004, 2006; Ellwood, 2000; Hotz and Scholz, 2003; Meyer and Rosenbaum, 2001; Rothstein, 2005). In their evaluation of the program's 1986 expansion comparing unmarried mothers to a control group of unmarried women without children, Eissa and Liebman (1996) found an increase in LFP of 6.1 percentage points. Employing a similar research design, Meyer and Rosenbaum (2001) compared the effect of the EITC program to federal welfare programs and found that the EITC accounted for 60 percent of the increase in LFP, with smaller shares of the increase due to economic growth, welfare benefit reductions, waivers, and childcare expenses.

Second, given that the design of the program is predicated on the earnings of the household, for married households, there is evidence that the EITC has a modest and

${ }^{9}$ Given that the credit is a proportion of the household's eligible earnings, the size of the credit for this population is notably smaller. In 2014, the maximum size of the credit for households without qualifying children was $\$ 496$, while households with 1,2 , and 3 or more children received $\$ 3,305, \$ 5,460$, and $\$ 6,143$, respectively. The credit rate for childless households was 7.65 percent compared to 34,40 , and 45 percent for the latter household structures (Tax Policy Center, "Taxation and the Family: What is the Earned Income Tax Credit?" http://www.taxpolicycenter.org/briefing-book/key-elements/family/eitc. $\mathrm{cfm})$. In addition, on average, households without children who are eligible for the EITC earn roughly 60 percent less than those eligible households with eligible children (Internal Revenue Service, "Earned Income Credit (EIC)," publication 596).

${ }^{10}$ The program has undergone a number of expansions; the Tax Policy Center offers updated information on the size of the program (Tax Policy Center, "Taxation and the Family: What is the Earned Income Tax Credit," http://www.taxpolicycenter.org/briefing-book/key-elements/family/eitc.cfm).

${ }^{11}$ This maximum credit for unmarried filers with two children in 2010 was $\$ 5,460$, while the maximum credit for unmarried filers with three children in 2010 was $\$ 6,143$ (Tax Policy Center, "Taxation and the Family: What is the Earned Income Tax Credit," http://www.taxpolicycenter.org/briefing-book/key-elements/ family/eitc.cfm). 
even negative effect for secondary workers. Scholars attribute this effect to the different set of incentives regarding labor activity for the married population. Using a research design similar to Eissa and Liebman (1996), who compared eligible married couples with children to ineligible married couples without children, Eissa and Hoynes (2004) found that the EITC expansions reduced household labor supply. For households with income near the upper bound of the EITC income threshold, evidence suggests that the EITC program may effectively be subsidizing the secondary earners to stay out of the workforce.

Third, results from analyses on the intensive margin for both married and unmarried households are ambiguous (Eissa and Hoynes, 2006; Eissa and Liebman, 1996; Hotz and Scholz, 2003). Only a small number of papers have examined the impact of the EITC on weeks worked, given that this estimation strategy poses greater empirical challenges. Not only do researchers find it difficult to deal with the selection of individuals into the labor force, but they also find it hard to identify the empirical change in the number of weeks worked, given the difficulty of modifying weeks worked and the aggregated comparison of means approach typically used (Eissa and Hoynes, 2006).

Taken together, the evidence suggests that the impact of the EITC program on LFP has a heterogeneous treatment effect that depends on the structure of the qualifying household. These studies share not only a dependent variable - labor activity - but also an empirical approach exploiting EITC expansions to examine the short-run impact of the program. The validity of this design rests on the assumption that the expansion is unanticipated for the recipient household and is therefore plausibly exogenous. To strengthen the design, many studies use a control group that is ineligible for the EITC program as a reference group.

This approach is subject to two criticisms. First, researchers are limited to exploiting legislative expansions in the program - 1986, 1990, 1993, 2001, and 2009 - with the majority of studies focused on the first three. Second, the validity of a DD design hinges on the identification of a defensible control group. Studies analyzing the most prominent target population - less educated, unmarried mothers - typically rely on unmarried women without children as the control group. Despite efforts to match on observable measures, this approach has methodological shortcomings. Blundell and MaCurdy (1999) stress that women without children participate in the workforce closer to their upper bound compared to unmarried mothers since women without children do not have child-rearing constraints. Moreover, Ellwood (2000, p. 1074) highlights that "the temporal trends in labor force participation of the women with and without children are often different before the enactment of the EITC, so drawing inferences from differential trends afterwards is troubling."

We do not intend to discount these studies; rather, we aim to extend the discussion with an empirical approach that considers the after effects of the program. We exploit variation in the size of the credit when a household loses eligibility because qualifying children age out of the program. While we examine the short-run effect of EITC 
reduction, this offers a framework for assessing if the primary goal of the program - incentivizing work - extends beyond the tenure of the program. We focus this study on one of the largest groups of EITC recipients - unmarried, less educated mothers - where the literature has found the program to increase LFP (Dickert, Houser, and Scholz, 1995; Eissa and Hoynes, 2004, 2006; Ellwood, 2000; Meyer and Rosenbaum, 2001; Rothstein, 2005). Given that households can be eligible for this credit for up to 18 years (or even longer for households with multiple children or with children that attend college) we expect that the extended tenure of the credit may have a lasting effect for the treatment group in terms of adjusting the filers' taste for work. ${ }^{12}$

Our research design circumvents the two criticisms highlighted above. First, by focusing on the loss of EITC eligibility, our empirical approach is not constrained to examine programmatic change. This approach allows for a more recent assessment of the program by looking at labor activity from 1996 to 2010, which includes but is not limited to the most recent major expansions in 2001 and 2009. Moreover, by exploiting household variation in the size of the EITC over time, we can include household fixed effects to control for unobserved time-invariant factors.

\section{RESEARCH DESIGN}

This study focuses on the effect of EITC reduction on LFP. We exploit variation in the size of the credit based on the qualifying child requirement, specifically when qualifying children age out of the program. This scenario occurs when a household's second youngest and then youngest child turn age 19 , respectively. ${ }^{13}$ If the children are enrolled full time in college, program eligibility extends until the child turns age 24 . We note that loss of eligibility is not random and depends both on household choices and EITC program design. Thus, we draw from a series of life-cycle labor supply studies that rely on exogenous and anticipated tax changes contingent on the household requirement to justify this approach (Feldman, Katuscak, and Kawano, 2016; Looney and Singhal, 2006; Mulligan, 1999).

This section is organized as follows. We begin by presenting the data and sample. Next, we identify the targeted treated population. Then, we discuss plausible design threats to the empirical approach. Critical to this design is the assumption that changes in LFP are only attributed to EITC reduction for households with the second youngest and youngest child losing eligibility, respectively.

12 Dowd and Horowitz (2011) find evidence that households claim EITC at varying rates; however, as we expect, low-income households - with unmarried mothers in particular — demonstrate longer periods of use compared to other households.

13 After 2009, the EITC program created a differential benefit for families with three or more eligible children. We focus on two eligible children given that our time frame ranges from 1996 to 2010. Moreover, there were very few households with three eligible children in 2010. 


\section{A. Data and Sample}

We use the NLSY79 dataset, a national survey conducted by the Bureau of Labor Statistics. ${ }^{14}$ Given the household requirement for the EITC program, this is a particularly useful data source to examine the effect of EITC reduction and/or exit on labor activity. The survey initially used multiple respondent households where all eligible individuals age 14 to 21 in the household at the end of 1978 were included as individual respondents. ${ }^{15}$ After the initial survey in 1979, individuals were interviewed about themselves and their family members annually until 1994, and biennially thereafter with all time-varying questions referring to the previous calendar year. We use the more recent data from 1996 to 2010. The NLSY79 oversamples civilian blacks, Hispanics, and the economically disadvantaged non-black/non-Hispanic population. This is a useful population for our analysis, given that it targets households more likely eligible for the EITC.

We rely on the sample of households with one to four children between ages 6 to 33. We selected this specific population of households for a number of reasons. First, our identification strategy focuses on households with children. Second, we exclude households with more than four children to maintain a relatively homogenous household structure. Labor decisions are likely different among larger households; in addition, households with five or more children are outliers in our sample. ${ }^{16}$ Third, we exclude observations for respondents with any children under age 6 due to the expected additional time constraints of having young children (Gelbach, 2002). ${ }^{17}$ Moreover, we extend the age cutoff to 30 for the youngest child and to 33 for older siblings for the following reasons: ${ }^{18}$ (1) to capture eligibility changes at age 19 (or 24, assuming college enrollment applies); (2) to include observations in the post-treatment period; and (3) to exclude mothers post-retirement. While children with disabilities qualify for the

\footnotetext{
${ }^{14}$ In 1979 the NLSY79 surveyed 12,686 men and women between the age 14 to 22 in three subsamples. The largest group was comprised of 6,111 individuals representative of the U.S. non-institutionalized civilian youth population, the second consisted of 5,295 individuals with an oversample of civilian Hispanic, black, and economically disadvantaged non-black/non-Hispanic youths, and the third surveyed 1,280 military youths enlisted in the armed forces.

${ }^{15}$ Respondents were then interviewed each survey year with information collected on their current spouse and children. Information on other individuals in the family unit after the base year survey is recorded under the respondent's identification number, not as a separate record. While most of the households with multiple respondents were comprised of siblings, there were also 334 respondents that were spouses in the same household.

${ }^{16}$ Ninety-five percent of married and 93 percent of unmarried households with children have four or less children, respectively.

${ }^{17}$ The minimum requirement for primary school varies across state; the average age of enrollment is age 6 (National Center for Education Statistics, "Table 5.3 Types of State and District Requirements for Kindergarten Entrance and Attendance, by State: 2014,” http://nces.ed.gov/programs/statereform/tab5_3.asp).

${ }^{18}$ We considered extending the age cutoff beyond age 33; however, the distribution of children's ages trails off at this point. We excluded those older than age 33 given that they are outliers to the sample.
} 
program regardless of age, the NLSY79 does not have information on disability status. Thus, our measure of eligibility has some measurement error, which may attenuate the estimates.

\section{B. Selection of Treatment Group}

Considerable scholarly and policy attention has been placed on a specific population of recipients - unmarried, less educated mothers. Not only are they the most relevant group for studying whether the EITC reduces welfare dependency, but unmarried mothers are also the group for which we can most plausibly ignore the joint labor supply decisions of other family members and accordingly derive simple predictions from labor supply theory (Meyer and Rosenbaum, 2001). We follow the literature and identify eligible households with unmarried, less educated mothers. We operationalize this by stratifying the head of household filer by gender, filing status, and education. Recent research has found little empirical evidence that the EITC has altered marriage or family formation rates (Baughman and Dickert-Conlin, 2003, 2009; Dickert-Conlin and Houser, 2002; Eissa and Hoynes, 1998; Ellwood, 2000; Evans and Garthwaite, 2014). Therefore, we are not concerned about selection into treatment - in terms of EITC eligibility - across this dimension.

We stratify by educational attainment to provide a proxy for the EITC income eligibility, since stratifying by contemporaneous income is endogenous with our dependent variable, LFP. Specifically, we stratify by the head of household's modal value of education over the 1996 to 2010 time frame. ${ }^{19}$ Earlier EITC research stratified by less than a high school education to identify the eligible population (Eissa and Hoynes, 2006; Eissa and Liebman, 1996; Meyer and Rosenbaum, 2001); however, more recent studies have increased the education threshold to high school or equivalent (Averett and Wang, 2013; Evans and Garthwaite, 2014). In earlier iterations of this work, we stratified by both characteristics and found robust results. However, we present the results from the more inclusive stratification to follow the more recent scholarship.

Figure 1 shows a kernel density of the income distribution for unmarried mothers stratified by educational attainment ranging from less than high school to college. This figure offers convincing evidence that EITC eligibility is inversely related to educational attainment. To be clear, we do not directly measure EITC with this sample, but rather identify the sample most likely intended for treatment using education and household structure as a proxy for eligibility. Not surprisingly, the treatment effect is more diluted as the educational attainment increases; for instance, 85 percent of those with a high school education or less had earnings below the EITC maximum income threshold, while only 47 percent of those with a college education or more were below the threshold. In other words, unmarried mothers with a high school education or less comprise the purest EITC treatment group for this sample, leaving unmarried mothers with a college

${ }^{19}$ In the event the head of household has two modal values, we selected the lower level of attainment. Only 4 percent of women in the sample changed their education category during the 1996 to 2010 time period. 


\section{Figure 1}

\section{Income by Educational Attainment for Unmarried Mothers}

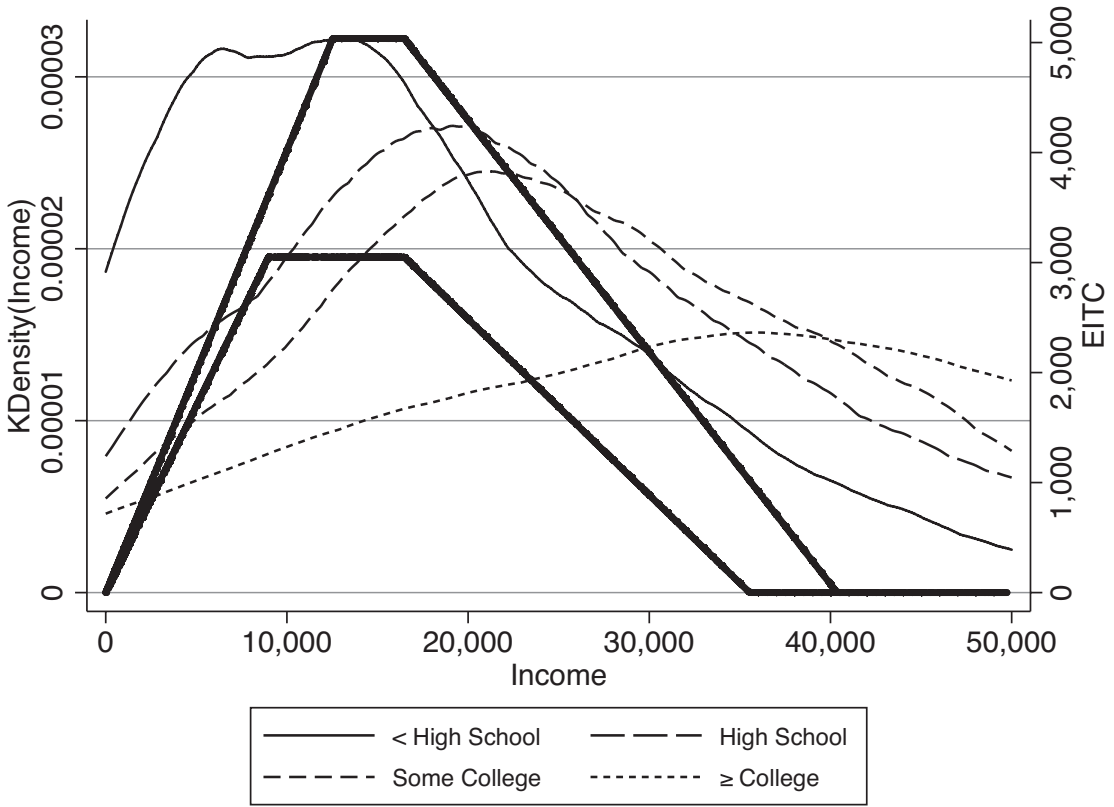

Notes: Kernel density of household earned income in 2010(\$) for unmarried women is stratified by educational status. The window is $\$ 1$ to $\$ 50,000$. EITCs for one- and two-children families in 2010 are shown in thick lines. The smaller and taller trapezoids refer to families with one and two children, respectively.

Source: NLSY79 1996-2010 — unmarried mothers

education as the most defensible control for unmarried mothers. ${ }^{20}$ We recognize that this comparison is imperfect, yet the structure of the household is similar. We strengthen this design with the inclusion of household fixed effects.

Table 1 presents descriptive statistics for unmarried mothers. Again, these unmarried mothers have one to four children between ages 6 to 33. To approximate the treatment and control groups, we stratify by education in Columns 1 and 2, respectively. LFP is the primary outcome; this measure is derived from the respondents' reported number of weeks worked in the previous calendar year as one if a respondent worked any weeks and

${ }^{20}$ There may be concern that more educated mothers have children at later ages. However, there is only a 2.8-year difference between the age of unmarried, college educated women and unmarried, less-than-highschool educated women when their youngest child ages out (age 46.3 compared to age 43.5). 


\begin{tabular}{|c|c|c|c|c|}
\hline \multicolumn{5}{|c|}{$\begin{array}{c}\text { Table } 1 \\
\text { Summary Statistics }\end{array}$} \\
\hline & \multicolumn{2}{|c|}{ (1) } & \multicolumn{2}{|c|}{ (2) } \\
\hline & \multicolumn{2}{|c|}{$\leq$ High School } & \multicolumn{2}{|c|}{$\geq$ College } \\
\hline Labor force participation & 0.77 & $(0.42)$ & 0.93 & $(0.26)$ \\
\hline Income (mean \$) & 18,003 & $(22,173)$ & 40,375 & $(38,969)$ \\
\hline Income (median \$) & 13,165 & & 34,000 & \\
\hline Mother's age & 42.49 & $(5.13)$ & 43.72 & $(5.06)$ \\
\hline Black & 0.47 & $(0.50)$ & 0.46 & $(0.50)$ \\
\hline Hispanic & 0.21 & $(0.41)$ & 0.12 & $(0.33)$ \\
\hline AFDC & 0.07 & $(0.25)$ & 0.02 & $(0.15)$ \\
\hline Food stamps & 0.20 & $(0.40)$ & 0.05 & $(0.21)$ \\
\hline Child 1 college & 0.23 & $(0.42)$ & 0.65 & $(0.48)$ \\
\hline Child 2 college & 0.17 & $(0.38)$ & 0.48 & $(0.50)$ \\
\hline Child 3 college & 0.13 & $(0.34)$ & 0.57 & $(0.50)$ \\
\hline Child 4 college & 0.06 & $(0.25)$ & 0.80 & $(0.45)$ \\
\hline $\mathrm{N}$ & 5,639 & & 1,162 & \\
\hline Unique $\mathrm{N}$ & 1,423 & & 307 & \\
\hline
\end{tabular}

zero otherwise. We report a series of household characteristics for illustrative purposes, given that many of these characteristics are time-invariant and therefore incorporated into the model with the household fixed effects.

\section{Identification}

The strength of this research design lies in the following assumption: the head of household's LFP is solely a function of EITC reduction as approximated by the second youngest and/or youngest eligible child aging out of the program. In other words, we assume that LFP is not a function of potential contemporaneous factors that result from the qualifying children aging from 18 to 19 (or, in the case of those children enrolled full time in college, aging from 23 to 24). Critics to this design may be concerned that children aging from 18 to 19 , who are at a time in their life that shortly follows high school graduation, affect the head of household's LFP. To justify this approach, we rely on a series of diagnostic tests and draw from the literature. 
In terms of mechanisms, one may be concerned that unmarried mothers may retire when their children complete high school, given that these women represent an older workforce cohort. The average age for the entire sample, however, is 42.7 , and the average age when the youngest child becomes ineligible for the EITC is 46 with the $99^{\text {th }}$ percentile at age 53 . Thus, we have little concern that aging into conventional retirement ages affects our estimates. We recognize, though, that intertemporal substitution may confound the results, as women may be more likely to change careers after their children graduate. Nevertheless, the binary design of the outcome metric obviates this. ${ }^{21}$

From another angle, some may be concerned that women are more likely to enter the workforce when their children complete high school given that they have fewer household responsibilities. To examine this phenomenon, we compare LFP rates for unmarried mothers with less education with children aging from 18 to 19. We focus on age variation for their children who are not the second youngest or youngest - specifically, we consider the age transition of the oldest child in households with three to six dependents. Importantly, these children do not affect EITC eligibility, yet their age poses a plausibly comparable impact on the household in terms of potential changes to household structure. This approach serves as a falsification test for our identification strategy. Results from a comparison of means tests indicate that the average rates of LFP for women with children age 18 as compared to children age 19 are slightly different (0.001), but the difference is not statistically different from zero. We argue that these null results offer preliminary evidence that the head of household's labor decisions are not a function of the fact that their children from age 18 to 19 , and therefore age variation of the second youngest and youngest child is an appropriate estimate for EITC variation and income reduction. Exploiting this particular variation on the treatment group is our closest approximation to the counter-factual. ${ }^{22}$

A number of studies that have employed methods similar to ours offer convincing evidence that parental labor supply does not change as children enter adulthood (Feldman, Kawano, and Katuscak, 2016; Looney and Singhal, 2006; Mulligan, 1999). For example, in estimating life cycle effects for families who lose AFDC eligibility, Mulligan (1999) justifies the use of a "qualifying child" indicator by arguing that the $18^{\text {th }}$ birthday of the youngest child is not associated with changes in health, "tastes," productivity, or other variables for the parents. Although the $18^{\text {th }}$ birthday is one year before the EITC eligibility cutoff, we would suspect that, if there were to be a life event effect, it would be more pronounced at age 18 rather than age 19 given that legal status changes at this

\footnotetext{
${ }^{21}$ To reiterate, the metric is coded one if the mother worked any weeks in a given year. If the mother was changing careers when her child turned age 19 and therefore was out of the labor force, we would only be able to track this change if she were unemployed for more than one calendar year. At that point, we argue it is sufficient to assume she is out of the labor force.

${ }^{22}$ With this approach, there are still at least two children in the house. So while we exploit within variation for the treatment group, responses to LFP may be different for the younger children. To address this limitation, we also consider unmarried college educated mothers as a counter-factual. This control group is included in the DD model. These results are presented in the next two sections.
} 
cutoff. Nevertheless, Mulligan does not find evidence to support this. Looney and Singhal (2006) discuss the effect of intertemporal labor supply elasticities on life cycle labor supply activity. The authors consider the effect of EITC participation among married households by exploiting variation in program eligibility based on the qualifying child requirement. They rely on empirical evidence from a series of comparisons demonstrating that parental labor supply does not change for parents in control groups who are ineligible for the policy with children at the same age. As illustrated above, we follow this approach examining variation within eligible populations and find similar results.

A related line of research focuses on the economic relationship between young adult children and their parents and has found consistency in family dynamics as children age into adulthood (Goldscheider, Thornton, and Yang, 2001). Aquilino (2005) found evidence to suggest that midlife parents continue to provide economic support to their children into the child's early years of adulthood, though the commitment is greater among households with married parents. This study offers evidence that the family dynamics - specifically those that pertain to the demands of parental labor supply remain unchanged as the child enters adulthood.

Taken together, we argue that the factor of children aging from 18 to 19 alone does not change the head of household's LFP. While we recognize that high school graduation is a notable life event for a child and his or her family, we do not find evidence that this event affects LFP for unmarried, less educated mothers. Thus, we argue that the variation in the youngest child's age serves as a valid measure to assess the effect of a reduction in income on LFP.

\section{METHODS}

We estimate two sets of models to examine the effect of the EITC on LFP. The first is a household fixed effects model that exploits within household variation based on change in the child's age. The second builds upon this model and incorporates a DD design to include a control group of ineligible unmarried mothers with a higher level of education.

Equation (1) is a household fixed effects model estimating the impact of the number of EITC qualifying children on LFP. For this model, we restrict the sample to unmarried mothers with a high school education or less.

$$
Y_{i t}=\alpha_{i}+\beta_{1} 1 \text { ELIGIBLE }_{i t}+\beta_{2} 2 \text { ELIGIBLE }_{i t}+\text { Year }_{t}+\varepsilon_{i t} .
$$

We control for general macroeconomic shocks to the labor market using survey year fixed effects, Year $r_{t}$ The year fixed effects also capture the effect of aging on the respondent's LFP because age and year are collinear. We control for time-invariant household factors with household fixed effects, $\alpha_{i}$. The dependent variable, $Y_{i t}$, is the extensive margin of labor supply (LFP).

Variation in the qualifying child's eligibility based on age serves as our key independent variable of interest. The age of each child was derived using the year of birth, 
survey year, and, if applicable, year of death of each child. 1 ELIGIBLE $E_{i t}$ is an indicator variable equal to 1 when the household has only one child between age 6 and 18 , resulting in one qualifying child. $2 E L I G I B L E_{i t}$ is an indicator variable equal to 1 when the household has two or more children between age 6 and 18, resulting in two qualifying children for the EITC. The omitted category is when the household's children are over age 18 , resulting in no qualifying children. Thus, $\beta_{2}$ estimates the effect of having two EITC qualifying children compared to zero and $\beta_{1}$ estimates the effect of having one EITC qualifying child compared to zero.

The EITC serves both to increase the wage and income of recipients. Theoretically, the reduction of the EITC from losing eligible children lowers the wage leading to lower LFP due to a lower cost of leisure (substitution effect). Yet the EITC reduction also lowers income that could lead to higher LFP to counteract the reduction in income. While both effects are likely at play, the income effect may not be as dominant if households can recover this loss by other means - such as other public assistance programs, including the TANF/AFDC program for eligible households. ${ }^{23}$

Most papers investigating EITC find an increase in female LFP when the household experiences an increase in the generosity of the credit from a program expansion (e.g., Eissa and Hoynes, 2004; Eissa and Liebman, 1996; Meyer and Rosenbaum, 2001). If the response is also similar when using time varying, within household variation in the reduction of the credit, then we expect the absolute value of the coefficient $\beta_{2}$ to be larger than the coefficient $\beta_{1}$ because the EITC is larger for two qualifying children than one. The marginal effect between two and one eligible children can be calculated by the difference between $\beta_{2}$ and $\beta_{1}$. To operationalize this, we use two binary variables to account for qualifying children as opposed to a variable of number of qualifying children. ${ }^{24}$ The latter implies a linear relationship, which is not appropriate in this case given the non-linear rates of EITC for income by number of eligible children. ${ }^{25}$

Equation (2) is a hybrid model including a DD and household fixed effects. ${ }^{26} \mathrm{We}$ stratify on education to determine the treatment and control groups. Unmarried mothers with a high school education or less serve as the treatment group and, based on the results from the kernel density of income distribution (Figure 1), unmarried mothers with a college education serve as the control. The sample for this model therefore is

\footnotetext{
${ }^{23}$ Family and Social Services Administration, "Temporary Assistance for Needy Families," http://www. in.gov/fssa/dfr/2684.htm. See also Maag, Rennane, and Steurele (2011) for a useful overview of social programs for children.

${ }^{24}$ We have also used a single indicator variable equal to one for any eligible children and get similar estimates.

${ }^{25}$ There is a large difference in the amount of the credit between a household with no children and a household with one child, and a smaller increase when going from one to two children. In 2009, the EITC was expanded to include a small increase from two to three children. See Internal Revenue Service, "2015 EITC Income Limits, Maximum Credit Amounts and Tax Law Updates," http://www.irs.gov/Individuals/ EITC-Income-Limits,-Maximum-Credit--Amounts-and-Tax-Law-Updates for more information on the EITC.

${ }^{26}$ This hybrid model may also be referred to as a triple differences model with one treatment dimension being education and the other the number of eligible children.
} 
larger. To distinguish clearly between the treatment and control groups, we exclude the sample of recipients with some college education.

$$
\begin{aligned}
& \text { (2) } Y_{i t}=\alpha_{i}+\beta_{1} 1 \text { ELIGIBLE }_{i t}+\beta_{2} 2 \text { ELIGIBLE }_{i t}+\beta_{3}(E D U C A T I O N \leq 12)\left(1 \text { ELIGIBLE }_{i t}\right) \\
& +\beta_{4}(E D U C A T I O N \leq 12)\left(2 \text { ELIGIBLE }_{i t}\right)+\text { Year }_{t}+\varepsilon_{i t} .
\end{aligned}
$$

The outcome variable $\left(Y_{i t}\right)$, household fixed effects $\left(\alpha_{i}\right)$, and year dummies $\left(\right.$ Year $\left.{ }_{t}\right)$ estimate components similar to those in (1). Moreover, the estimation approach of the qualifying children - for one and two - is similar with $\beta_{1}$ and $\beta_{2}$ in (1) reflecting the estimated differences in LFP for one and two qualifying children, respectively, compared to zero, but now for the control group. The coefficient for (FemaleED $\leq 12)\left(1 E L I G I B L E_{i t}\right)$, $\beta_{3}$, estimates how much further the outcome for the treatment group (high school or less) deviates from zero qualifying children compared to the control group's deviation; $\beta_{4}$ estimates this same deviation for the treatment group with two qualifying children. The parameters of interest are estimated by $\beta_{3}$ and $\beta_{4}$, which measure the change in LFP due to variation in EITC eligibility for the treatment group compared to the control group.

We include both models given their unique yet complementary attributes. The household fixed effects model explicitly exploits within household variation. Following the EITC literature, we also include the hybrid model; this places the results in context to a control group. We suspect the true effect of EITC reduction is bracketed by these two estimations.

For both models, we employ a Linear Probability Model (LPM). This approach is used instead of a logit model due to our use of a fixed effects model and the ease of interpreting marginal effects; additionally out-of-range predictions do not pose an empirical concern with this analysis. ${ }^{27}$ The standard errors are clustered at the household level. The sample size ranges from 1,421 to 1,730 unique heads of household for the main results; this depends on the stratification employed and model.

\section{RESULTS}

\section{A. Household Fixed Effects Estimates}

The results from Column 1 of Panel A in Table 2 report the estimated coefficients for (1). The results for the qualifying children — one and two - are positive, though only statistically significant for the former. The statistically significant results indicate that losing one EITC qualifying child decreases LFP by 3.3 percentage points compared to households with no qualifying children. ${ }^{28}$

27 There were no out-of-range predictions using the LPM model.

${ }^{28}$ Note that, given that we rely on EITC reduction, we interpret the LFP results in a manner that may seem opposite to the coefficients in the tables. 


\section{Table 2}

Main Results

Child Eligible Until Age:

Panel A. Fixed Effects Model (Equation 1)

\begin{tabular}{lcc}
\hline IELIGIBLE & $0.033^{*}$ & $0.045^{* *}$ \\
2ELIGIBLE & $(0.018)$ & $(0.020)$ \\
& 0.028 & $0.047^{*}$ \\
$\mathrm{~N}$ & $(0.025)$ & $(0.026)$ \\
Unique N & 5,639 & 5,624 \\
\hline
\end{tabular}

Panel B. Hybrid - DD and Fixed Effects Model (Equation 2)

\begin{tabular}{lcc}
\hline$(E D U C A T I O N \leq 12) \times(1 E L I G I B L E)$ & $0.080^{* * *}$ & $0.089^{* *}$ \\
$(E D U C A T I O N \leq 12) \times(2 E L I G I B L E)$ & $(0.023)$ & $(0.036)$ \\
& $0.105^{* * *}$ & $0.202^{* * *}$ \\
1 ELIGIBLE & $(0.031)$ & $(0.041)$ \\
& $-0.039^{* *}$ & -0.039 \\
2 ELIGIBLE & $(0.020)$ & $(0.032)$ \\
& $-0.065^{* *}$ & $-0.144^{* * *}$ \\
$\mathrm{~N}$ & $(0.029)$ & $(0.039)$ \\
Unique N & 6,801 & 6,786 \\
\hline
\end{tabular}

Notes: Estimates are included in Column 1 assuming a child is eligible until age 19 or age 24 in Column 2. Panel A includes estimates from a household fixed effects model (1), including indicators for number of qualifying children (less than age 19 or age 24) and survey year for single mothers with a high school education or less. Panel B estimates (2); this includes interactions between the numbers of qualifying children and an indicator for whether the respondent was in the treatment group (had a high school education or less). Unmarried mothers with at least a college education serve as the control group in Panel B. Standard errors in parentheses are clustered at the household level. Asterisks denote significance at the $1 \%(* * *), 5 \%(* *)$, and $10 \%(*)$ levels.

Source: NLSY79 1996-2010 — unmarried mothers 


\section{B. Hybrid DD Household Fixed Effects Estimates}

Column 1 of Panel B in Table 2 reports the coefficients for (2). The sample for this model is larger and includes the control group of unmarried, college educated mothers. In contrast to (1), this model exploits a pre- and post-comparison group design. The coefficients for the treatment group are positive and statistically significant for both one and two qualifying children. The differential effect of EITC reduction, due to the youngest child aging out of the program, is an average decrease in LFP of a statistically significant 8 percentage points. Moreover, the differential effect of EITC reduction, due to the loss of two qualifying children, is associated with a decrease of 10.5 percentage points. Both of these results are compared to those less likely to be eligible for the program. We estimate the loss of two qualifying children as a preliminary step to derive the marginal impact of EITC reduction when the second youngest child ages out, yet the household remains eligible for a smaller credit. The difference between the coefficients for two and one eligible children, however, is not statistically significant. The estimates for the control group are the opposite sign and relatively smaller; however, they are statistically significant.

\section{Additional Specifications}

We examine the impact of variation in the number of EITC qualifying children across two dimensions as additional specification measures. First, we assess variation in the timing of the shock to account for families whose children attend college, thus extending the benefit period. Second, we stratify by household structure - in terms of the number of children - to see if there is a heterogeneous treatment effect across households with one, two, three, or four children, respectively, for unmarried mothers with a high school education or less.

\section{College Attendance}

Thus far, the empirical analysis has ignored the possibility of college attendance prolonging the household's EITC eligibility until the child turns age 24. Treating households with children enrolled in college past age 18 as if they have lost their EITC eligibility would attenuate the estimates toward zero since these parents would still be receiving the EITC and would theoretically have no need to adjust their LFP.

We adjust our assumption and extend EITC eligibility to age 23. While we do have self-reported data on college attendance for dependent children, we want to account for families that may be misled by the form or choose incorrectly to extend their benefit. Thus, we apply the extended cutoff to the full sample (Chetty and Saez, 2013). ${ }^{29} \mathrm{Col}-$ umn 2 in Table 2 reports the results for (1) (Panel A) and (2) (Panel B), respectively.

${ }^{29}$ While Chetty and Saez (2013) did not explicitly focus on the requirement, results from their randomized experiment of 43,000 EITC recipients suggest that tax preparers can influence how recipients file for the credit. No additional enrollment information is needed for the filer to extend the credit from age 18 to 23; the filer simply needs to check a box that the dependent is less than age 24 and is a student. For instance, see Box 4a of the 2006 EIC form (www.irs.gov/pub/irs-prior/f1040sei--2006.pdf). The form has not changed over the course of our sample (for the 1998 form, see www.irs.gov/pub/irs-prior/f1040sei--1998.pdf) and is very similar to the form used in 2014 (www.irs.gov/pub/irs-pdf/f1040sei.pdf). 
The result for one qualifying child is positive and statistically significant, indicating that LFP decreases by 4.5 percentage points when the youngest child loses eligibility. The differential effect of EITC reduction on LFP due to the loss of two qualifying children is associated with a decrease of 4.7 percentage points. The difference between these two coefficients is not statistically significant.

In Column 2 of Panel B in Table 2, we present the coefficients for (2). The coefficients for the treatment group are robustly positive and significant with an estimated decrease in LFP by 8.9 and 20.2 percentage points, respectively, for the loss of one and two qualifying children. For the control group, the coefficients are the opposite sign and are statistically significant for the two qualifying children. Just as with the age 19 cutoff, we recognize that this control group - while the most appropriate when considering income - is still not a clean control group since some of the respondents are eligible for the EITC, and this group is not as comparable to less educated households.

\section{Household Size Stratification}

The results in Panel A of Table 3 report the coefficients for (1) for unmarried mothers with a high school education or less stratified by the number of children. ${ }^{30}$ The sample size ranges from 170 to 529 . We interpret the results with caution given the small sample size, especially for one-, three-, and four-children stratifications. The results point to a potential heterogeneous treatment effect by household structure. Notably, the coefficients are not significant for households with one, three, or four children. For households with two children, the results are positive and statistically significant such that losing one EITC qualifying child decreases LFP by 7 percentage points, and losing two EITC qualifying children decreases LFP by 8.1 percentage points.

For households with three or four children, the direction of the coefficient is positive, but the size is notably smaller and not significant. We argue that these households have a different set of tradeoffs than households with one or two children since they are more likely income constrained (see average and median incomes at the top of Table 3 ). These lower incomes suggest that these families are potentially eligible for AFDC/ TANF benefits and are deciding between not working and receiving AFDC/TANF versus working and receiving the EITC. Given these tradeoffs, we suspect the results are noisier for these larger families.

Regarding households with one child, there is evidence to suggest that these children have a higher college attendance rate and therefore could remain eligible for the credit until they turn age $24 .{ }^{31}$ Thus, it is more likely that for one-child families the EITC credit is extended to the college cutoff at age 24 so we would expect to see the effect from the loss of the credit at this later age as opposed to age 19.

\footnotetext{
${ }^{30}$ We also run (2) stratified by household size and find similar results; these results are presented in Table A1.

${ }^{31}$ Approximately, one-third of children in one-child households in the treatment group attend college, which is roughly twice the proportion of those in two- to four-child households. The proportion attending college falls with family size.
} 


\section{Table 3}

Fixed Effects Model Stratified by Number of Children

\begin{tabular}{lcccc}
\hline & $(1)$ & $(2)$ & $(3)$ & $(4)$ \\
& 1 Child & 2 Children & 3 Children & 4 Children \\
\hline Income (mean \$) & 18,956 & 20,301 & 16,032 & 12,967 \\
Income (median \$) & 15,000 & 16,000 & 10,000 & 5,000 \\
\hline
\end{tabular}

Panel A. Child Eligible until Age 19 (Equation 1)

\begin{tabular}{lcccc}
\hline IELIGIBLE & -0.030 & $0.070^{* * *}$ & 0.039 & 0.043 \\
& $(0.038)$ & $(0.027)$ & $(0.033)$ & $(0.062)$ \\
EELIGIBLE & & $0.081^{* *}$ & 0.027 & 0.027 \\
$\mathrm{~N}$ & & $(0.038)$ & $(0.051)$ & $(0.072)$ \\
Unique N & 1,360 & 2,133 & 1,569 & 642 \\
\hline
\end{tabular}

Panel B. Child Eligible until Age 24 (Equation 1)

\begin{tabular}{lcccc}
\hline 1ELIGIBLE & $0.069^{* *}$ & -0.003 & 0.06 & 0.085 \\
& $(0.03)$ & $(0.03)$ & $(0.042)$ & $(0.103)$ \\
2 ELIGIBLE & & -0.038 & $0.108^{* *}$ & 0.119 \\
& & $(0.039)$ & $(0.05)$ & $(0.114)$ \\
$\mathrm{N}$ & 1,360 & 2,133 & 1,554 & 642 \\
Unique N & 352 & 529 & 376 & 170 \\
\hline
\end{tabular}

Notes: Estimates are for those with high school education or less and are stratified by total number of children. The estimates are from a household fixed effects model (1) including indicators for number of qualifying children (less than age 19 - Panel A - or less than age 24 - Panel B) and survey year. Asterisks denote significance at the $1 \%(* * *), 5 \%(* *)$, and $10 \%(*)$ levels.

Source: NLSY79 1996-2010 — unmarried mothers

The results in Panel B of Table 3 extend the eligibility cutoff to age 24 and present the coefficients from (1). The result is positive and statistically significant for households with one child, indicating that losing the qualifying child decreases LFP by 6.9 percentage points. This supports our expectation, as these children are more likely to attend college and therefore are eligible for the extended credit. The coefficients are negative though not significant for households with two children. For households with three or four children, the coefficients are positive, yet the result is only significant for households with three children for the two qualifying children. Notably, losing two EITC qualifying children decreases LFP by 10.8 percentage points for households with three children. 


\section{DISCUSSION AND CONCLUSION}

This analysis expands the EITC literature by focusing on EITC reduction and exit. Considerable research has exploited variation in terms of EITC expansion; however, we examine whether the program has a lasting effect and adjusts one's taste for work. While the explicit intention of the program is to incentivize work, the implicit intention of this anti-poverty social program is that participants remain engaged in the workforce beyond their tenure of eligibility. We examine the after effects of the EITC program on workforce activity and identify unmarried, less educated mothers as our target treatment group. This approach complements the existing literature not only by focusing on a different policy dimension but also by considering the impact of the program for an older cohort of mothers with children entering adulthood. The household fixed effects and hybrid model with a DD research designs provide alternative robust approaches to studying the effects of this popular assistance program in a way that minimizes bias.

We find evidence suggesting that when children age out of EITC eligibility, some recipients leave the labor force. Specifically, losing one qualifying child decreases LFP by 3.3 percentage points. When comparing the treatment group to the control group of college educated, unmarried mothers, the effect is larger with an 8.0 percentage point decrease. We would like to note that our hybrid model (2) does in fact produce a larger effect than the fixed effect estimator. This suggests that unmarried, college educated mothers in fact increase their LFP when their child turns age 19. While prior studies have found that the EITC program is successful in promoting work, these results suggest that the labor supply for the intended treatment group responds to the removal of the incentive. This result also holds when we place the within household variation in contrast to an ineligible control group.

We include a series of additional specifications to assess whether there is a heterogeneous treatment effect with respect to household size. In addition, we assess variation in the timing of the shock to account for families whose children may attend college, thus extending the benefit period. For the former, we find that households with two children drive the effect when eligibility is contingent on the age 19 cutoff. This group is not only eligible to receive the largest share of the EITC but also accounts for the largest type of family structure in terms of the number of children. Thus, it is with a policy significant group that we find a statistically significant effect. As for the latter specification, we find evidence that the net effect is larger when we extend the credit to children turning age 24. We suspect these households are more likely to claim dependents until age 23 to extend the credit, even though only a small portion note that their children are enrolled in college. While data on the filing details for the EITC are not publicly available, this would be worth exploring in future research and would complement a growing line of literature on tax credits and college enrollment (Chetty, Friedman, and Rockoff, 2011; Manoli and Turner, 2014).

In addition, our limited findings for larger families may be indicative of an alternative set of tradeoffs. Families with three or four children have lower incomes on average, as compared to smaller families. This makes them potentially eligible for AFDC/TANF benefits. These families are making the trade off between some work and receiving the 
EITC and no work and receiving AFDC/TANF throughout their child's lifetime. Thus, their behavior is not comparable to smaller families. ${ }^{32}$

While our results indicate that some people leave the workforce when the EITC benefit stops, it is important to note that not everyone does. Eissa and Liebman (1996) find that LFP increased 6.1 percentage points for unmarried, less educated mothers using the 1986 EITC expansion, which increased the maximum EITC credit from \$550 to \$851 or a difference of \$598 in 2010 dollars. In this paper, the loss of the last remaining EITC qualifying child in 2010 for a family with the maximum credit was $\$ 3,050$. In a hypothetical scenario, if EITC exit were to impact the recipients equally but in the opposite direction, then we would suspect the exit to decrease LFP by over 30 percent. ${ }^{33}$ However, the largest effect we find is a decrease of 20.2 percent, with most results being much smaller. The difference implies that while the EITC fails to provide a taste for work for many women, it does for others, thereby increasing the labor force on net.

This article opens up avenues for additional research in a number of dimensions. First, future research could examine how EITC reduction affects married households. Moreover, with improved data, additional studies could examine this effect at the intensive margin. Second, several studies examine the effects of the EITC on outcomes other than labor; these include health outcomes and spending patterns (Averett and Wang, 2013; Evans and Garthwaite, 2014; Barrow and McGranahan, 2000; Smeeding, Phillips, and O'Connor, 2000). Future studies could build upon our empirical approach by analyzing these alternative outcomes. Third, future research could focus on the mechanisms of EITC reduction and LFP — specifically in examining how these lower income families respond to incentives and tradeoffs. Meyer and Rosenbaum (2001) offer a baseline for this type of analysis, but more updated research is warranted. In addition, in looking at an older cohort of mothers, how might intergenerational households weigh these tradeoffs? Are the children of unmarried mothers now supporting them since they are older, or are the unmarried mothers perhaps caregivers to grandchildren? These issues deserve greater attention.

\section{ACKNOWLEDGEMENTS}

We would like to thank Hilary Hoynes, Christine Durrance, and Scott Wentland for their helpful comments. All omissions and errors are our own. The authors contributed equally to this paper.

${ }^{32}$ More detailed data on social program assistance would enable us to examine this issue; however, this lack of detail is a limitation of our dataset. Maag, Rennane, and Steuerle (2011) offer a useful overview of federal child tax programs. While EITC eligibility ends at age 19 (for households whose children do not enroll full time in college), there are a number of programs that extend beyond this period that may impact LFP.

${ }^{33}$ We recognize that the economic conditions are different between these two periods and that this is a simple linear approximation; nevertheless, we include this as an illustrative thought experiment. 


\section{DISCLOSURES}

The authors received no financial support for this research and have no financial arrangements that might give rise to conflicts of interest with respect to the research reported in this paper.

\section{REFERENCES}

Aquilino, William S., 2005. "Impact of Family Structure on Parental Attitudes toward the Economic Support of Adult Children over the Transition to Adulthood." Journal of Family Issues $26(2), 143-167$.

Averett, Susan, and Yang Wang, 2013. "The Effects of Earned Income Tax Credit Payment Expansion on Maternal Smoking." Health Economics 22 (11), 1344-1359.

Barrow, Lisa, and Leslie McGranahan, 2000. "The Effects of the Earned Income Credit on the Seasonality of Household Expenditures.” National Tax Journal 53 (4, Part 2), 1211-1243.

Baughman, Reagan, and Stacy Dickert-Conlin, 2003. "Did Expanding the EITC Promote Motherhood?” American Economic Review 93 (2), 247-251.

Baughman, Reagan, and Stacy Dickert-Conlin, 2009. "The Earned Income Tax Credit and Fertility." Journal of Population Economics 22 (3), 537-563.

Blundell, Richard, and Thomas MaCurdy, 1999. "Labor Supply: A Review of Alternative Approaches." In Ashenfelter, Orley C., and David Card (eds.), Handbook of Labor Economics, Volume 3, Part A, 1559-1695. Elsevier Science B. V., Amsterdam.

Cancian, Maria, and Arik Levinson, 2006. "Labor Supply Effects of the Earned Income Tax Credit: Evidence from Wisconsin's Supplemental Benefit for Families with Three Children." National Tax Journal 59 (4), 781-800.

Chetty, Raj, John N. Friedman, and Jonah Rockoff, 2011. New Evidence on the Long-Term Impacts of Tax Credits. Internal Revenue Service, Washington, DC.

Chetty, Raj, and Emmanuel Saez, 2013. "Teaching the Tax Code: Earnings Responses to an Experiment with EITC Recipients." American Economic Journal: Applied Economics 5 (1), $1-31$.

Dickert, Stacy, Scott Houser, and John Karl Scholz, 1995. "The Earned Income Tax Credit and Transfer Programs: A Study of Labor Market and Program Participation." In Poterba, James M. (ed.), Tax Policy and the Economy, Volume 9, 1-50. MIT Press, Cambridge, MA.

Dickert-Conlin, Stacy, and Scott Houser, 2002. "EITC and Marriage." National Tax Journal 55 (1), 25-40.

Dowd, Tim, and John B. Horowitz, 2011. "Income Mobility and the Earned Income Tax Credit: Short-Term Safety Net or Long-Term Income Support.” Public Finance Review 39 (5), 619652 . 
Eissa, Nada, and Hilary Williamson Hoynes, 1998. "The Earned Income Tax Credit and the Labor Supply of Married Couples.” NBER Working Paper No. 6856. National Bureau of Economic Research, Cambridge, MA.

Eissa, Nada, and Hilary Williamson Hoynes, 2004. "Taxes and the Labor Market Participation of Married Couples: The Earned Income Tax Credit." Journal of Public Economics 88 (9-10), 1931-1958.

Eissa, Nada, and Hilary W. Hoynes, 2006. "Behavioral Responses to Taxes: Lessons from the EITC and Labor Supply.” In Poterba, James M. (ed.), Tax Policy and the Economy, Volume 20, 73-110. MIT Press, Cambridge, MA.

Eissa, Nada, and Jeffrey B. Liebman, 1996. "Labor Supply Responses to the Earned Income Tax Credit.” Quarterly Journal of Economics 111 (2), 605-637.

Ellwood, David T., 2000. "The Impact of the Earned Income Tax Credit and Social Policy Reforms on Work, Marriage, and Living Arrangements." National Tax Journal 53 (4, Part 2), 1063 1105 .

Evans, William N., and Craig L. Garthwaite, 2014. "Giving Mom a Break: The Impact of Higher EITC Payments on Maternal Health." American Economic Journal: Economic Policy 6 (2), 258-290.

Feldman, Naomi E., Peter Katuscak, and Laura Kawano, 2016. "Taxpayer Confusion: Evidence from the Child Tax Credit." American Economic Review 106 (3), 807-835.

Gelbach, Jonah B., 2002. "Public Schooling for Young Children and Maternal Labor Supply." American Economic Review 92 (1), 307-322.

Goldscheider, Frances K., Arland Thornton, and Li-Shou Yang, 2001. "Helping Out the Kids: Expectations about Parental Support in Young Adulthood." Journal of Marriage and Family 63 (3), 727-740.

Hotz, V. Joseph, Charles H. Mullin, and John Karl Scholz, 2002. "Welfare, Employment, and Income: Evidence on the Effects of Benefit Reductions from California." American Economic Review 92 (2), 380-384.

Hotz, V. Joseph, and John Karl Scholz, 2003. "The Earned Income Tax Credit." In Moffitt, Robert A. (ed.), Means-Tested Transfer Programs in the United States, 141-198. University of Chicago Press, Chicago, IL.

Hotz, V. Joseph, and John Karl Scholz, 2006. "Examining the Effect of the Earned Income Tax Credit on the Labor Market Participation of Families on Welfare." NBER Working Paper No. 11968. National Bureau of Economic Research, Cambridge, MA.

Looney, Adam, and Monica Singhal, 2006. "The Effect of Anticipated Tax Changes on Intertemporal Labor Supply and the Realization of Taxable Income.” NBER Working Paper No. 12417. National Bureau of Economic Research, Cambridge, MA. 
Maag, Elaine, Stephanie Rennane, and C. Eugene Steuerle, 2011. A Reference Manual for Child Tax Benefits. The Urban Institute, Washington, DC.

Manoli, Dayanand S., and Nicholas Turner, 2014. "Cash-on-Hand and College Enrollment: Evidence from Population Tax Data and Policy Nonlinearities.” NBER Working Paper No. 19836. National Bureau of Economic Research, Cambridge, MA.

Meyer, Bruce D., 2002. "Labor Supply at the Extensive and Intensive Margins: The EITC, Welfare, and Hours Worked.” American Economic Review 92 (2), 373-379.

Meyer, Bruce D., and Dan T. Rosenbaum, 2001. "Welfare, the Earned Income Tax Credit, and the Labor Supply of Single Mothers." Quarterly Journal of Economics 116 (3), 1063-1114.

Mulligan, Casey B., 1999. "Substitution over Time: Another Look at Life-Cycle Labor Supply." In Bernanke, Ben S., and Julio J. Rotemberg (eds.), NBER Macroeconomics Annual 1998, Volume 13, 75-152. MIT Press, Cambridge, MA.

Rothstein, Jesse, 2005. "The Mid-1990s EITC Expansion: Aggregate Labor Supply Effects and Economic Incidence.” Working Paper No. 883. Princeton University, Princeton, NJ.

Scholz, John Karl, 1994. "The Earned Income Tax Credit: Participation, Compliance, and Antipoverty Effectiveness.” National Tax Journal 47 (1), 63-87.

Scholz, John Karl, 1996. "In-Work Benefits in the United States: The Earned Income Tax Credit." Economic Journal 106 (434), 156-169.

Smeeding, Timothy M., Katherin Ross Phillips, and Michael A. O'Connor, 2000. "The EITC: Expectation, Knowledge, Use, and Economic and Social Mobility." Center for Policy Research Working Paper No. 13. Center for Policy Research, Denver, CO. 


\section{APPENDIX}

\section{Table A1}

Hybrid Model Stratified by Number of Children

(2)

(3)

(4)

1 Child 2 Children 3 Children 4 Children

Panel A. Child Eligible until Age 19 (Equation 2)

\begin{tabular}{|c|c|c|c|c|}
\hline$(E D U C A T I O N \leq 12) \times(1 E L I G I B L E)$ & $\begin{array}{c}0.058 \\
(0.041)\end{array}$ & $\begin{array}{c}0.134 * * * \\
(0.035)\end{array}$ & $\begin{array}{l}-0.026 \\
(0.059)\end{array}$ & $\begin{array}{c}0.089 \\
(0.116)\end{array}$ \\
\hline$(E D U C A T I O N \leq 12) \times(2 E L I G I B L E)$ & & $\begin{array}{c}0.150 * * * \\
(0.040)\end{array}$ & $\begin{array}{c}0.056 \\
(0.072)\end{array}$ & $\begin{array}{c}0.027 \\
(0.109)\end{array}$ \\
\hline $1 E L I G I B L E$ & $\begin{array}{c}-0.066^{* *} \\
(0.031)\end{array}$ & $\begin{array}{c}-0.061 * * \\
(0.029)\end{array}$ & $\begin{array}{c}0.065 \\
(0.052)\end{array}$ & $\begin{array}{l}-0.026 \\
(0.101)\end{array}$ \\
\hline $2 E L I G I B L E$ & & $\begin{array}{c}-0.064 * \\
(0.035)\end{array}$ & $\begin{array}{l}-0.036 \\
(0.070)\end{array}$ & $\begin{array}{c}0.026 \\
(0.120)\end{array}$ \\
\hline $\mathrm{N}$ & 1,816 & 2,538 & 1,752 & 695 \\
\hline Unique $\mathrm{N}$ & 463 & 650 & 428 & 189 \\
\hline
\end{tabular}

Panel B. Child Eligible until Age 24 (Equation 2)

\begin{tabular}{lcccc}
\hline EDUCATION $\leq 12) \times(1$ ELIGIBLE $)$ & $0.104 * *$ & 0.042 & 0.161 & 0.077 \\
& $(0.048)$ & $(0.074)$ & $(0.124)$ & $(0.163)$ \\
$($ EDUCATION $\leq 12) \times(2 E L I G I B L E)$ & & $0.184 * * *$ & $0.220^{* *}$ & $0.290^{* *}$ \\
1 ELIGIBLE & & $(0.064)$ & $(0.088)$ & $(0.114)$ \\
& -0.022 & -0.035 & -0.092 & 0.008 \\
2 ELIGIBLE & $(0.042)$ & $(0.069)$ & $(0.117)$ & $(0.114)$ \\
& & $-0.201 * * *$ & -0.109 & $-0.159^{* * *}$ \\
$\mathrm{~N}$ & & $(0.063)$ & $(0.083)$ & $(0.057)$ \\
Unique N & 1,816 & 2,538 & 1,737 & 695 \\
& 463 & 650 & 426 & 189
\end{tabular}

Notes: Estimates are for those with an education of high school or less and are stratified by number of children. Columns 1-4 denote one to four children, respectively. Estimates are from the hybrid DD, fixed effects model (2) that includes interactions between number of qualifying children and whether the respondent had education less than or equal to high school, with unmarried college serving as the control. Panel A considers children eligible until they turn age 19, while Panel B uses an age 24 cutoff. Standard errors in parentheses are clustered at the household level. Asterisks denote significance at the $1 \%(* * *), 5 \%(* *)$, and $10 \%(*)$ levels.

Source: NLSY79 1996-2010 — unmarried mothers 